\title{
Growth and Endocrine Disorders Secondary to Cranial Irradiation
}

\author{
RAPHAËL RAPPAPORT AND RAJA BRAUNER
}

Pediatric Endocrinology and Diabetes Unit and INSERM U.30, Hôpital des Enfants-Malades, Paris, France

\begin{abstract}
External cranial radiation for the treatment of malignant diseases has become a frequent cause of growth hormone deficiency (GHD). The timing of occurrence and the frequency of GHD were related to the hypothalamic-pituitary radiation dose. Frequency varied from $50 \%$ in leukemia ( $2400 \mathrm{cGy})$ to $75 \%$ in face and neck tumors or medulloblastoma (2500-4500 cGy) and up to $100 \%$ in optic glioma (>4500 cGy). The significantly more severe growth deficit in patients with GHD given higher radiation doses suggests different levels of residual $\mathrm{GH}$ secretion according to radiation dosage. The minimum harmful radiation dose is probably close to $1800-2000$ cGy. Our data show that stimulation tests remain a useful means of defining GHD and predicting growth. A fair agreement between GH secretion and growth was found in most cases, regardless of the radiation dose. The only exception was a group of leukemic children (2400 cGy) who achieved normal prepubertal growth despite a low GH response. The $24-\mathrm{h}$ spontaneous plasma $\mathrm{GH}$ profiles and IGF-I measurements may add information if growth is retarded despite a normal GH response. We showed that growth retardation occurring after some schedules of total body irradiation was not due to GH deficiency but rather to radiation-induced skeletal lesions. Early or true precocious puberty, generally associated with GHD, was another cause of height loss. As the role of GH deficiency in the final height reduction was demonstrated in all groups of patients after cranial radiation, we suggest that hGH therapy should be considered in any child with proven GH deficiency and significant growth retardation after such radiation. (Pediatr Res 25: 561-567, 1989)
\end{abstract}

\section{Abbreviations}

GH, growth hormone

TBI, total body irradiation

GHSP, GH secretory profile

ALL, acute lymphoblastic leukemia

GHRH, GH releasing hormone

TSH, thyroid-stimulating hormone

AIST, arginine-insulin stimulation test

External cranial irradiation has proven to be a major tool in the treatment of various malignant diseases. Many treatment protocols incorporate cranial irradiation; these protocols differ according to the causal disease. High radiation doses are used to

Received December 9, 1988; accepted January 12, 1989

Correspondence and reprint requests Dr. R. Rappaport, Pediatric Endocrinology Unit, Hôpital des Enfants Malades, 149 Rue de Sèvres, 75743 Paris Cedex 15, France.

Supported by grants from INSERM (contract PRC 1982) and the Association pour la Recherche contre le Cancer (ARC 451-1984). treat brain tumors such as optic gliomas, ependymomas, medulloblastomas, and face and neck malignant tumors such as nasopharyngeal sarcomas or retinoblastomas. The protocols used for more than a decade to treat acute lymphoblastic leukemia (ALL) involve lower radiation doses. The newer technique of bone marrow transplantation preconditionning by TBI was first applied to leukemic children but has now extended to nonmalignant conditions, including hematologic, metabolic, and immunologic disorders.

Although these therapies have significantly improved the survival rate in a large number of children, the growth retardation resulting from radiotherapy has become a matter of concern. All cranial radiation protocols included the hypothalamic-pituitary axis, and it has been clear, since the earliest studies (1-3), that such radiation impaired $\mathrm{GH}$ secretion. Other endocrine disorders have been described depending on the initial disease and the total radiation dose delivered to the hypothalamic-pituitary area (Table 1). Growth retardation is considered to be mainly due to GH deficiency, although other factors, including impaired skeletal growth and precocious puberty, may also have an impact on final height.

\section{GROWTH HORMONE DEFICIENCY}

Frequency. The first case of induced hypopituitarism and growth retardation in children after cranial radiation for a tumor distant from the hypothalamic-pituitary region was reported in 1966 (4), and was followed quickly by several other reports (512). It soon became apparent that irradiation of the hypothalamus and the pituitary gland resulted in a high incidence of $\mathrm{GH}$ deficiency and growth retardation. The frequency of $\mathrm{GH}$ deficiency was reported to vary according to the initial disease and the effective biologic dose of radiation reaching the hypothalamopituitary region. An inverse correlation was found between that dose and the plasma $\mathrm{GH}$ response to pharmacologic stimulation $(3,13)$. We have found that $56 \%$ of a group of children given 2400 cGrays (Gy or rad) as prophylactic irradiation for ALL had $\mathrm{GH}$ deficiency, with a $\mathrm{GH}$ peak response to the arginine-insulin stimulation test (AIST) less than $8 \mathrm{ng} / \mathrm{ml}$ (Table 1). Complete $\mathrm{GH}$ deficiency with two consecutive $\mathrm{GH}$ peak responses less than $5 \mathrm{ng} / \mathrm{ml}$ was observed in $30 \%$ of the same population. The $\mathrm{GH}$ response to AIST of eight children more recently treated with a radiation dose of 1800 cGy remained normal at least 4 y after irradiation (Fig. 1). This radiation schedule is presently more frequently used and deserves further evaluation. We also found normal GH secretion in another group of children treated for retinoblastoma when the radiation dose delivered to the pituitary region was less than $2000 \mathrm{cGy}$ (14). The frequency of $\mathrm{GH}$ deficiency is much higher in children given cranial doses above $2400 \mathrm{cGy}$; we found a frequency of about $75 \%$ in children treated with up to $4500 \mathrm{cGy}$. All of a group of children irradiated for optic glioma with doses above $4500 \mathrm{cGy}$ had GH deficiency (15). Thus, the total radiation dose is an important variable for the risk of pituitary dysfunction, as are the fractionation schedule 
Table 1. Endocrine abnormalities after external cranial irradiation*

\begin{tabular}{|c|c|c|c|c|c|c|c|}
\hline \multirow[b]{3}{*}{ Etiology } & \multirow{3}{*}{$\begin{array}{c}\text { Radiation } \\
\text { cGy }\end{array}$} & \multirow{3}{*}{$\begin{array}{c}\text { Cases } \\
(n)\end{array}$} & \multicolumn{5}{|c|}{ Percentage of cases with endocrine abnormality } \\
\hline & & & \multicolumn{2}{|c|}{$\begin{array}{l}\text { GH peak } \\
(\mathrm{ng} / \mathrm{ml})\end{array}$} & \multirow[b]{2}{*}{ Thyroid $\dagger$} & \multirow[b]{2}{*}{$\mathrm{ACTH}$} & \multirow[b]{2}{*}{ Puberty } \\
\hline & & & $<5$ & $5-8$ & & & \\
\hline \multirow[t]{2}{*}{ Leukemia } & 1800 & 8 & 0 & 0 & 0 & 0 & 0 \\
\hline & -2400 & 86 & 30 & 22 & 2 & 0 & 3 \\
\hline Face and neck tumors & $\begin{array}{r}2500 \\
-4500\end{array}$ & 56 & 46 & 22 & 35 & 7 & 16 \\
\hline Medulloblastoma & $\begin{array}{r}2500 \\
-4500\end{array}$ & 59 & 52 & 24 & 47 & 8 & 20 \\
\hline Optic glioma & $\begin{array}{r}4500 \\
-5500\end{array}$ & 39 & 77 & 23 & 46 & 3 & 40 \\
\hline
\end{tabular}

* All patients were evaluated at least 4 y after irradiation.

$\dagger$ Includes high plasma TSH values when the neck had also been exposed to irradiation.

\& Frequency evaluated in patients with pubertal age. We have not included chemotherapy or radiation induced primary gonadal failure.

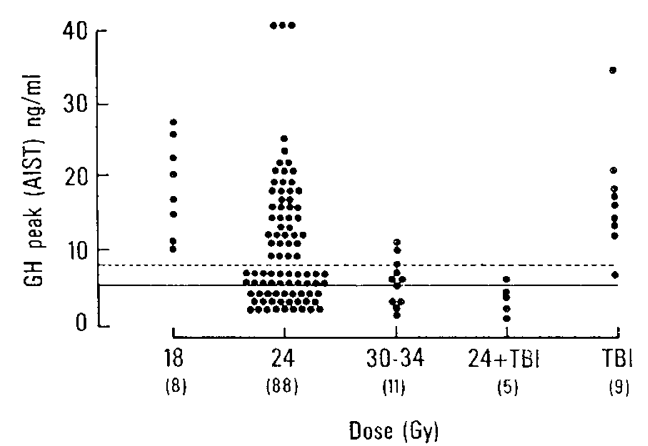

Fig. 1. GH responses to an AIST in 121 children treated for acute lymphoblastic leukemia according to their therapeutic protocol. They were studied at least $4 \mathrm{y}$ after irradiation except for those given TBI, who were followed for shorter intervals. The TBI groups received $1000 \mathrm{cGy}$ in a single exposure. The dotted $(8 \mathrm{ng} / \mathrm{ml})$ and the solid $(5 \mathrm{ng} / \mathrm{ml})$ lines represent the conventional values of the $\mathrm{GH}$ peak in partial and complete $\mathrm{GH}$ deficiency.

and the duration of the radiation therapy (16). In children treated with low range radiation doses the apparent frequency of $\mathrm{GH}$ deficiency may also depend on the type of stimulation testing: impairment of $\mathrm{GH}$ response to insulin-induced hypoglycemia but not to arginine stimulation was reported after $2400 \mathrm{cGy}$ by some $(17,18)$ but not other investigators (19).

The age at time of cranial irradiation is another important risk factor for $\mathrm{GH}$ deficiency because it has been shown that younger children are more vulnerable than older ones $(13,20)$. Furthermore, according to two prospective studies of patients given radiation doses of more than $3000 \mathrm{cGy}$, children $(21,22)$ appeared to develop GH deficiency more rapidly than adults (23).

The issue of the harmful radiation dose is also quite critical in children given TBI as conditioning for bone marrow transplantation. Early reports indicated that complete or partial $\mathrm{GH}$ deficiency was a frequent complication $(24,25)$. However, GH deficiency would be expected in many of these children who had already received cranial irradiation with 1800 to 2900 cGy. Partial GH deficiency could be attributed to TBI itself in only a few cases (24). The effect of the radiation dose in TBI was further evaluated by comparing different radiation protocols. We observed only one child of the 25 with a low GH response to AIST within $1 \frac{1}{2}$ and $7 \mathrm{y}$ after irradiation with up to $1000 \mathrm{cGy}$ given in a single exposure, or $1200 \mathrm{cGy}$ given as fractionated doses (26). We concluded that the radiation doses presently used as conditioning for bone marrow transplantation did not impair $\mathrm{GH}$ secretion.

The timing of occurrence of $\mathrm{GH}$ deficiency also is related to the radiation dose. Deficiencies may appear during the first year after radiation in patients irradiated with doses above $4500 \mathrm{cGy}$ $(15,22)$ and most of these children were $\mathrm{GH}$ deficient within 2 or 3 y. A prospective study of patients given $3100-4200$ cGy doses for medulloblastoma, revealed that the first significant decrease in $\mathrm{GH}$ response to stimulation occurred at the 12-mo evaluation, and $60 \%$ of the cases had GH deficiency at the 24mo follow-up (21). In our experience with a group of patients irradiated for brain tumors, GH deficiency almost always appears within $5 \mathrm{y}$. It should be added that no child has spontaneously recovered from $\mathrm{GH}$ deficiency. An early transient reduction in nocturnal $\mathrm{GH}$ secretion after prophylactic cranial radiation with $2000-2400 \mathrm{cGy}$ has been reported for a small number of patients (27).

Diagnosis. Most of the reported data on $\mathrm{GH}$ secretion in irradiated children have been based on the GH response to stimulation tests. Another approach to diagnosis of GH deficiency is the 24 hour spontaneous plasma GHSP on the assumption that such a diurnal pattern provides a better diagnostic tool of GH deficiency (28). A low GHSP has been observed in leukemic patients given prophylactic cranial radiation treatment (29) and in experimental studies on irradiated monkeys (30). However, the relative diagnostic value of an abnormal GHSP as compared with stimulated levels of $\mathrm{GH}$ remains controversial according to a recent study in normal short prepubertal children (31). Using the AIST we found that only $56 \%$ of a group of 86 prepubertal children irradiated with $2400 \mathrm{cGy}$ had a low GH response (32) (Fig. 1). In that group a normal $\mathrm{GH}$ response to stimulation was associated with normal or minimally impaired growth before puberty. Moëll et al. (33), in contrast, have observed GHSP to be substantially blunted in all cases of a group of 13 girls irradiated for ALL and studied before or during puberty.

The GH data for children who have been irradiated with doses in excess of $2400 \mathrm{cGy}$ probably are easier to interpret. We found that the spontaneous $\mathrm{GH}$ night peaks and peak responses to AIST of a group of 34 prepubertal children were significantly correlated (Fig. 2). Only five children had reduced spontaneous peaks despite normal responses to stimulation (34). Similarly in another study, all children with a blunted $\mathrm{GH}$ response to insulininduced hypoglycemia were found to have a reduced GHSP (35). Thus, pharmacologic tests of $\mathrm{GH}$ secretion remain a useful means of obtaining biochemical evidence of traditionally defined GH deficiency in these patients, and to predict growth retarda- 


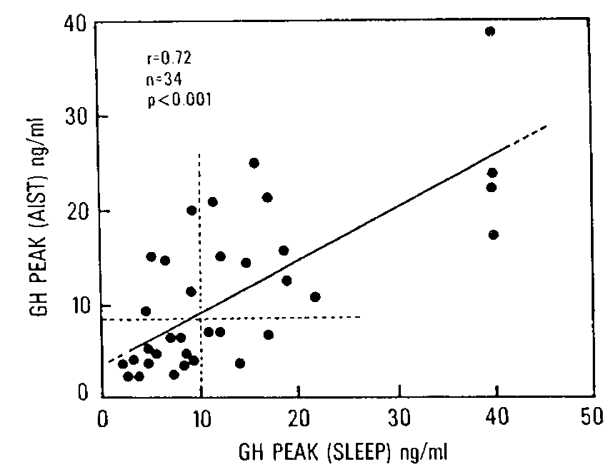

Fig. 2. Comparison between the GH response to an AIST and the spontaneous night peak $\mathrm{GH}$ values in 34 children given cranial radiation doses of 3200 to $4000 \mathrm{cGy}$ (34). They were studied at least 2 y after irradiation. The dotted lines represent the conventional lower limit of normal in prepubertal children for each test. Reproduced with permission (34).

tion. It has not been shown that GHSP is a more reliable technique to identify children at risk for growth retardation after cranial irradiation.

Plasma IGF-I values might be another useful parameter for evaluating $\mathrm{GH}$ secretion after cranial radiation. The plasma IGFI values of patients irradiated with 3100 to $4200 \mathrm{cGy}$ were in agreement with the $\mathrm{GH}$ response to provocative tests (21). We performed a similar comparison 4 y or more after a $2400 \mathrm{cGy}$ irradiation for ALL. The IGF-I values in this group tended to be at the lower limit of the normal range for age before puberty and more severely decreased during puberty, irrespective of the $\mathrm{GH}$ response to AIST (Fig. 3). A similar trend for low IGF-I was reported in one recent study (36) but not found in another (33). From our data, it is tempting to suggest that the low IGF-I values found in the leukemic patients reflected a decreased $\mathrm{GH}$ secretion before and during puberty. However, the cytostatic chemotherapy may have played a role in reducing the circulating IGF-I concentration: this possibility is currently being investigated.

Possible mechanisms. Reduced GH secretion has been considered to be the result of GHRH deficiency due to damage to the hypothalamus. Earlier experimental studies in rats and monkeys provided pathologic evidence that the hypothalamus and higher neural centers were more radiosensitive than the pituitary gland $(37,38)$. However GHRH stimulation of $\mathrm{GH}$ production after cranial irradiation has produced results, which varied with the radiation dose, time interval since radiation and the etiology of the underlying disease (39-41). All the patients irradiated with high doses (5000 cGy or more) had a very low response to GHRH, whereas children treated with 2400 cGy were still able to secrete $\mathrm{GH}$ in response to $\mathrm{GHRH}$, although the response was lower than that of short-stature control children $(33,42)$. These data provide evidence for both pituitary and hypothalamic damage. Other evidence for hypothalamic damage includes the observations that 1) plasma prolactin levels may be elevated (43), 2 ) the rise in TSH after thyrotropin-releasing hormone stimulation is elevated and delayed, 3) adrenocortical function is subnormal although the corticotropin response to corticotropin releasing factor is normal $(44), 4$ ) there is a discrepancy between GH secretion responses to insulin and arginine (see above), and 5) physiologic $\mathrm{GH}$ secretion is severely blunted despite a normal $\mathrm{GH}$ response to arginine and L-dopa in irradiated monkeys (30) and in some patients (29). The positive growth response to longterm GHRH 1-29 therapy also is consistent with a predominant hypothalamic lesion (45). However, a pituitary lesion cannot be excluded by the GHRH stimulation test as a single pulse cannot demonstrate the ability of pituitary cells to produce new $\mathrm{GH}$. Also there is a negative relationship between the GHRH-stimulated $\mathrm{GH}$ response and the time after radiotherapy, which may indicate late pituitary failure.

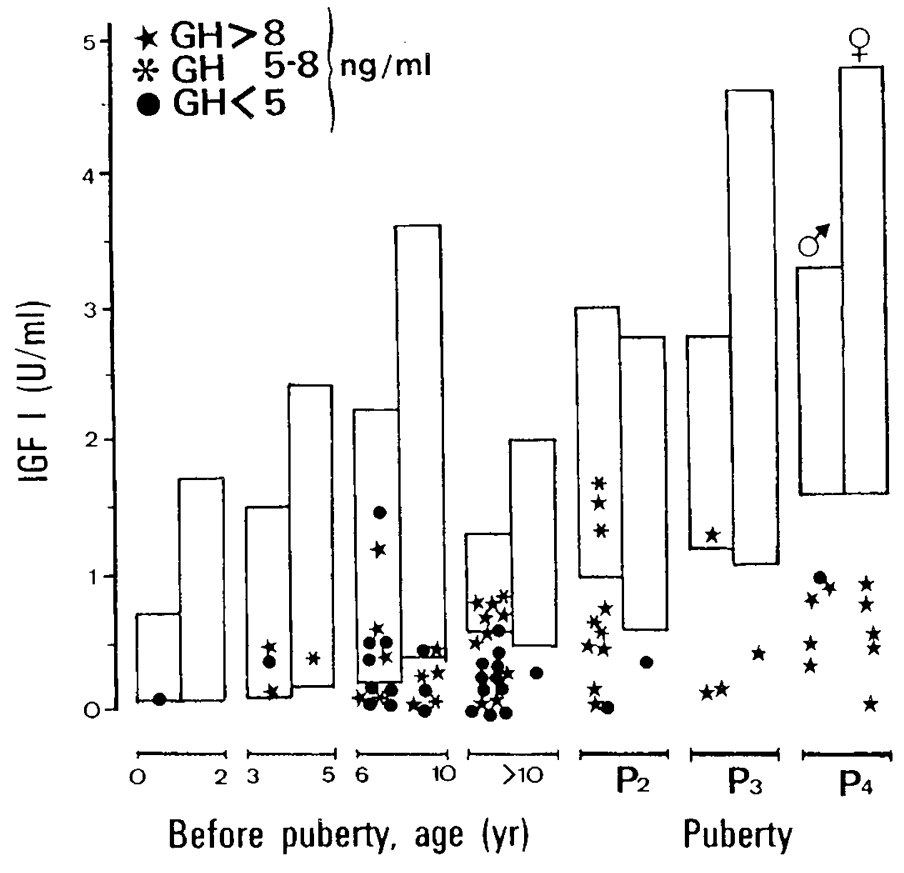

Fig. 3. Plasma IGF I (Sm-C) values in 74 children prophylactic 2400 cGy of cranial irradiation for acute lymphoblastic leukemia (stars, asterisks and dots). IGF I measurements were made in unextracted plasma samples as previously published (21). GH peak responses were obtained after an arginine-insulin stimulation test. The open bars show the range of values for age in normal children.

\section{PUBERTAL DEVELOPMENT}

Cranial radiation may alter gonadotropin secretion in different and opposite ways. It may produce gonadotropin deficiency with a loss or pertubation of pubertal development $(43,46,49)$ or may cause precocious puberty (50). Hyperprolactinemia also may alter normal reproductive physiology at a later age (43). The risk of gonadotropin deficiency also depends on the radiation dose. Only five of 45 children treated with 2500-5000 cGy doses before or during puberty showed a complete gonadotropin deficiency at pubertal age, and two children presented evidence of partial gonadotropin deficiency. Documented gonadotropin deficiency usually was associated with GH deficiency $(43,46,47)$. Until more extended follow-up studies are performed, the true frequency of hypogonadism in these children may be underestimated.

The $\mathrm{LH}$ and FSH responses to LHRH in children treated with 2000-2500 cGy for ALL were found to be normal (51). These data are consistent with the normal pubertal progression observed in most of these girls. Those few exceptions that occurred could be accounted for by chronic illness or wt loss (48). Only hypergonadotropic hypogonadism was reported in the group of children treated with TBI, indicating the lack of hypothalamic and pituitary failure (52). Elevated plasma prolactin levels have been reported in adults given high doses of cranial irradiation $(43,46)$. But, similar changes have been infrequent in children or adolescents $(47,48)$. True precocious puberty initially was reported in children given high radiation doses (more than 2500 cGy) for brain tumors (50). We have now extended this group to 11 children, three boys and eight girls. Three of them had received $2400 \mathrm{cGy}$ as prophylactic irradiation for ALL. Precocious puberty was associated with $\mathrm{GH}$ deficiency in all but two children. Premature puberty also occurred in children treated with radiation doses as low as $1800 \mathrm{cGy}(53)$. Other than overt true precocious puberty, there also is a trend toward an earlier onset of puberty and first menses in girls (51). Premature activation of puberty may indicate a primary hypothalamic defect which would be in agreement with the suppressive effect of 
luteinizing hormone-releasing hormone analog treatment in these cases.

\section{OTHER ENDOCRINE DISORDERS}

Other anterior pituitary endocrine functions are much less frequently impaired than $\mathrm{GH}$ secretion, and multiple endocrine deficiencies are more prevalent in patients who have received high radiation doses (Table 1). Interestingly, diabetes insipidus has not been reported after cranial irradiation. Hypothyroidism with low serum thyroxin and low TSH levels is quite infrequent. In such a patient a lack of TSH response to thyroid-releasing hormone would be due to pituitary failure, whereas a delayed response is more compatible with a primary hypothalamic lesion. However, very few of the patients presenting with these changes are hypothyroid. The elevated basal TSH seen in some patients with medulloblastoma or face and neck tumors is due to primary hypothyroidism secondary to direct irradiation of the thyroid (54). Corticotropin deficiency with clinical symptoms also is a rare complication. Almost all of the children we have investigated had a normal cortisol response to insulin-induced hypoglycemia and it appears that only a few patients among those irradiated with high cranial doses required hydrocortisone replacement therapy.

\section{GROWTH AFTER CRANIAL RADIATION}

The effect of cranial radiation on growth has been recently reviewed $(2,3)$. Most studies have attempted to correlate growth with $\mathrm{GH}$ secretion, and there is fair agreement between the two in children given high radiation doses. The problem is more complex in children treated with low doses of radiation; these children may show moderate growth retardation, but only a few are really at risk for short stature. Growth also involves factors unrelated to GH secretion. Spinal irradiation in children with medulloblastoma impairs growth as does diffuse cartilage plate exposure during TBI.

Growth after high-dose cranial radiation. Radiation treatment for brain or head and neck tumors, which results in hypothalamic-pituitary radiation doses in excess of $3000 \mathrm{cGy}$, will reduce final height in most children (41). Most of these patients develop GH deficiency and, as discussed, the time of onset of the GH deficiency will vary. Also the time interval between irradiation and the onset of growth deficiency varies. In a prospective study, we found a minimal but significant decrease in height after $2 \mathrm{y}$ with a mean loss of 0.4 height $\mathrm{SD}$; individual values ranged from +0.4 to -1.2 SD. As $60 \%$ of the children had developed $\mathrm{GH}$ deficiency by that time it was concluded that GH deficiency remained largely asymptomatic during that early post irradiation interval (21). The mean height loss came close to 1.1 SD when the prepubertal follow-up was extended to $7 \mathrm{y}$. This resulted in an average final height loss of $1.6 \mathrm{SD}$ in patients who had not been treated with exogenous hGH. Patients with optic glioma given even higher radiation doses (4500 cGy or more), developed growth retardation more rapidly and a mean height loss of 1.1 SD was observed $2 \mathrm{y}$ after therapy. A total of $100 \%$ of these children manifested GH deficiency at that time. In children who had received additional spinal irradiation, as for the treatment of medulloblastoma, growth was more severely impaired (21).

Growth after low dose cranial radiation. Low radiation doses (ranging from 1800-2400 cGy) are prescribed for children with ALL as prophylactic therapy for CNS recurrence. The reports on the occurrence of growth retardation in these patients are conflicting and the issue has probably been confused by the difficulty in sorting out the influence of many factors, such as age at irradiation, pubertal status during the evaluation of growth, type of chemotherapy, and perhaps duration and severity of the initial disease. Furthermore, some of the reported differences may have been due to the heterogeneity of the patient population in terms of their total cranial radiation dose and fractionation schedule. The long-term effects of a total radiation dose of 2400 cGy have been most comprehensively investigated. A moderate height reduction occurred during the first 2 y after diagnosis, followed, after completion of chemotherapy, by a slight catchup growth (55). Thereafter, either a normal growth rate (55) or a persistent growth retardation (19) were observed. The mean height loss was close to $1 \mathrm{SD}$ after a $10-y$ follow-up. This mean height loss, as estimated mostly in prepubertal patients, results from a wide range of individual height losses.

As growth hormone deficiency remains the prime candidate for etiology of the growth retardation, we investigated the significance of $\mathrm{GH}$ responses to stimulation in relation to prepubertal growth. The growth of 38 children was followed over a 4-y prepubertal period, after completion of their chemotherapy (Fig. 4). Those who had a normal GH response $(n=14)$ had all maintained a normal growth rate. Therefore the response of $\mathrm{GH}$ to AIST appears to provide reliable information for predicting growth in normal responders. In contrast, the growth patterns of the children who were low responders (GH peak less than $5 \mathrm{ng}$ / $\mathrm{ml})$ varied greatly. One group $(n=13)$, including children who had lost $1 \mathrm{SD}$ or more in height after therapy, experienced a mean height loss of $1.5 \mathrm{SD}$ after $4 \mathrm{y}$. In contrast, 11 patients maintained a normal growth rate, and therefore did not differ in this respect from the normal GH responders.

It was somewhat surprising, as already mentioned (62), that so many children remained asymptomatic. This paradoxical growth was observed only in patients treated with low radiation doses. We therefore extended our study and compared the prepubertal height changes of this group (treated with $2400 \mathrm{cGy}$ ) with the heights of $\mathrm{GH}$-deficient patients given higher radiation doses. As shown in Figure 5 the height loss of patients treated for face and neck tumors and for optic gliomas was significantly more severe than in the leukemic group (63). These data suggest that despite a similarly low GH response to AIST children with low dose cranial radiation had varying levels of residual $\mathrm{GH}$ secretion and some of these children had adequate $\mathrm{GH}$ secretion to maintain normal height velocity.

Role of puberty. The pubertal growth of irradiated children has been less well documented. Most of the data have been obtained by comparing the figures for irradiated children with the prepubertal and final heights of untreated patients. It seems that growth retardation during puberty accounts for a total final height loss of 0.5 to $1 \mathrm{SD}$ in leukemic children (64), and probably slightly more in other patients if they are GH deficient. Although not demonstrated, it is likely that the height deficit during puberty would be aggravated by the severity of $\mathrm{GH}$ deficiency. This issue is quite critical in $\mathrm{GH}$-deficient patients presenting a true precocious puberty. They experience accelerated bone maturation that is not accompanied by an appropriate height gain and may end up with severely reduced final height (50). As a consequence of these rapid changes, all irradiated children should be monitored for their bone age progression and for signs of early puberty.

Other factors influencing growth. Many of the patients given cranial radiation receive other treatment as part of their initial treatment protocols. They are therefore exposed to additional factors which may interfere with the growth response to $\mathrm{GH}$ replacement therapy. The growth retardation due to spinal irradiation involving radiation doses above $2000 \mathrm{cGy}$ has been well documented in children suffering from medulloblastoma. An effect on sitting height, independent of GH deficiency and resulting in very short trunk length, has been observed (65-67). Spinal irradiation accounted for most of the growth retardation observed in the $2 \mathrm{y}$ after irradiation with a mean height loss of $1.3 \mathrm{SD}$ as compared to only $0.3 \mathrm{SD}$ in the cranial irradiated children (21). We estimated that a final height loss of $1.4 \mathrm{SD}$ could be attributed to the lack of spinal growth. Spinal growth was more impaired if the patients were less than 6 y old when irradiated (68).

Some patients given TBI also are at risk for growth retardation unrelated to GH deficiency (26). Growth can be impaired due 
to diffuse radiation-induced skeletal lesions; patients given a single $1000 \mathrm{cGy}$ radiation dose had retarded growth despite their normal GH secretion. A more extensive evaluation of growth after TBI currently is under way to assess the impact of different radiotherapy schedules on growth and pituitary function. Chemotherapy, as used in leukemic patients not given radiotherapy, has been reported to allow normal growth $(57,58,69)$. However, there is some question as to the adverse effect on growth of more recent intensive chemotherapy regimens (19, 55). They may have independent effects on growth and eventually play a role in the lack of sufficient catch-up growth observed in some leukemic patient. For leukemic patients our experience to date is summarized in Table 2 which shows the frequency of growth retardation and $\mathrm{GH}$ deficiency as observed in relation to treatment.

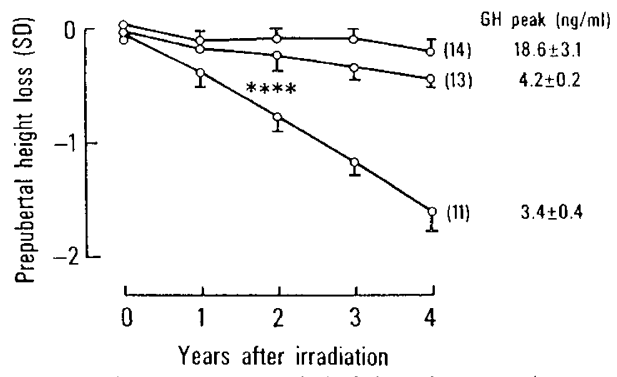

Fig. 4. Cumulative prepubertal height changes (expressed in SD score), in children treated with $2400 \mathrm{cGy}$ for acute lymphoblastic leukemia. The upper group $(n=14)$ included normal GH responders $(\mathrm{GH}$ peak $>8 \mathrm{ng} / \mathrm{ml}$ ). Patients in the two lower groups were $\mathrm{GH}$ deficient (GH peak $<5 \mathrm{ng} / \mathrm{ml}$ ). They were separated according to their height loss. (middle line $<I S D n=13$; lower line $>1 \mathrm{SD} n=11$.) See text. $* * * * p<0.001$ comparing the $>1$ SD group with $<1$ SD group.

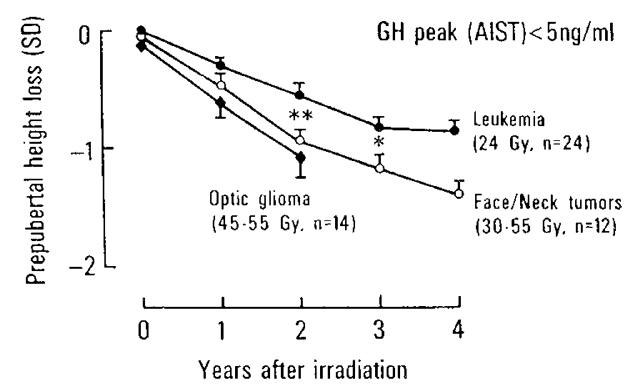

Fig. 5. Cumulative prepubertal height loss from irradiation according to their hypothalamic-pituitary radiation dose in three groups of children. All were $\mathrm{GH}$ deficient (GH peak response to arginine-insulin $<5 \mathrm{ng}$ / $\mathrm{ml})$. The mean ages at irradiation were similar in the three groups. Then $4 \mathrm{y}$ after irradiation a height loss of more than $1 \mathrm{SD}$ was found in 11 of 24 cases and 10 of 12 cases in leukemic and face or neck tumors group, respectively. The patients given $30-55$ Gy for face or neck tumors were significantly growth retarded as compared to the leukemic group $\left(^{*} p<\right.$ $\left.0.05,{ }^{* *} P<0.01\right)$. The optic glioma patients had slightly more severe and more rapid growth retardation.

\section{GROWTH HORMONE TREATMENT}

There are very few data on the final heights attained after spontaneous growth in cranial-irradiated children (41). We therefore performed a retrospective study to evaluate the height losses between irradiation and time of final height in children grouped according to their GH secretion (Fig. 6). The mean height losses in the untreated GH-deficient patients as compared to normal $\mathrm{GH}$ responders, were greater by $1.2 \mathrm{SD}$ (leukemic patients) and 1.0 SD (face or neck tumor patients). These data, despite the small number of patients studied, emphasize the need to consider GH treatment in irradiated children with $\mathrm{GH}$ deficiency.

Presently most agree that hGH treatment of children after cranial radiation produces annual height gains between 6 and 10 $\mathrm{cm}$ during the first year of treatment (70-72). These height gains are similar to those observed with treatment of children with idiopathic GH deficiency (73). However, this initial catch-up growth does not persist in subsequent years, leading to poor final height results. A mean decrease in standard height SD score of 0.2 SD between the onset of hGH therapy and the final height in cranial irradiated patients (74), and of 0.9 SD in craniospinal patients was reported recently (75). Our data (unpublished) confirm that prolonged $\mathrm{hGH}$ therapy does not significantly improve the mean height SD scores of patients given cranial or craniospinal irradiation. The differences in mean height gain in $\mathrm{hGH}$ treated patients were only 0.6 and 0.3 final height SD in cranial and craniospinal-irradiated patients, respectively, as compared to the untreated groups. There might be several reasons why the catch-up growth of these patients is less than that of children with idiopathic $\mathrm{GH}$ deficiency: 1 ) the cranial-irradiated patients have been GH-deficient for a shorter period, 2) their first year response, although significant, may already be lower than in idiopathic hypopituitarism (72), 3) their bone age was less retarded at the onset of GH therapy, 4) some had an earlier puberty, which accelerated the skeletal maturation faster than the increase in growth rate.

As a rule, it is essential to commence hGH therapy as soon as growth velocity declines, except for the initial post-radiation period when growth retardation is unlikely to be related to $\mathrm{GH}$ deficiency. We consider for hGH therapy any child with a height loss of $1 \mathrm{SD}$ or more since the time of irradiation, with proven $\mathrm{GH}$ deficiency and a follow-up period after radiation of 2 y or more. Appropriate therapy of thyroid deficiency also is necessary to optimize growth. Precocious puberty is an additional risk factor in some children and LHRH analog therapy should be considered in association with hGH administration. We are investigating whether this treatment schedule should be extended to patients with early onset of puberty alone. Final results may be improved if $\mathrm{hGH}$ treatment is started at an appropriate time and if current hGH dosages are employed with daily subcutaneous injections. An alternative approach has been proposed using daily GHRH treatment; encouraging short-term results on growth have been observed (45).

In summary, most, if not all, the children given high doses of cranial radiation should be treated with $\mathrm{hGH}$. Despite the reported poor results, cranio-spinal irradiated patients also should be treated, preferably before puberty to assure maximum growth

Table 2. Growth retardation in relation to GH deficiency before puberty in patients treated for acute lymphoblastic leukemia with cranial radiation (CR) or total body irradiation (TBI) as conditioning for bone marrow transplantation ( $n$ cases)*

\begin{tabular}{|c|c|c|c|c|}
\hline & $\begin{array}{c}\mathrm{CR} 1800 \mathrm{cGy} \\
(n=8)\end{array}$ & $\begin{array}{c}\text { CR } 2400 \text { cGy } \\
\quad(n=88)\end{array}$ & $\begin{array}{l}\text { TBI } 1000 \mathrm{cGy} \\
\quad(n=9)\end{array}$ & $\begin{array}{c}\text { TBI } 1000 \mathrm{cGy} \\
+ \\
\text { CR } 2400 \mathrm{cGy} \\
(n=5)\end{array}$ \\
\hline Peak GH AITT $<8 \mathrm{ng} / \mathrm{ml}$ & 0 & 46 & 1 & 5 \\
\hline Height loss $>1 \mathrm{SD}$ & 0 & 32 & 9 & 5 \\
\hline
\end{tabular}

${ }^{*}$ All patients were evaluated $>4 \mathrm{yr}$ after irradiation except for the TBI group (1000 cGy given in a single exposure) studied 1.5 to $7 \mathrm{y}$ after irradiation. 


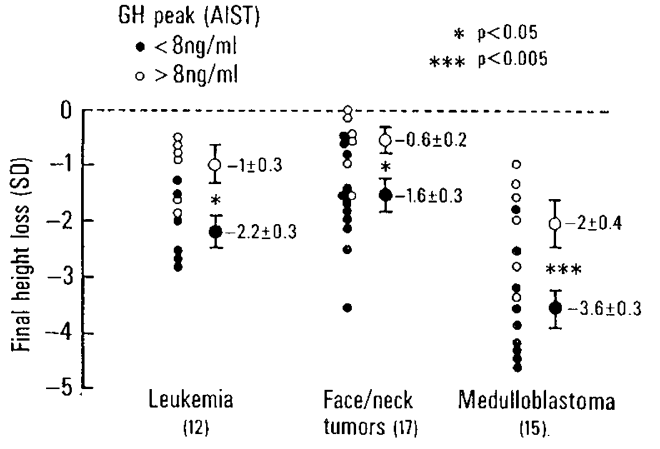

Fig. 6. Final height loss expressed as the difference between height SD score values at irradiation and at time of final height in untreated irradiated patients. Normal and low $\mathrm{GH}$ responders to stimulation $(\mathrm{GH}$ peak $<8 \mathrm{ng} / \mathrm{ml}$ ) were compared in each group. The mean height loss was significantly greater in the $\mathrm{GH}$-deficient patients in each group.

of the lower body segment. Children irradiated for ALL are less frequently candidates for GH therapy as their potential height loss generally is moderate. However, we have shown that some of these children do develop GH deficiency and will have a height loss of $1 \mathrm{SD}$ or more even before puberty. If these patients also are constitutionally short they are at risk of severe short stature if their growth and pubertal development are not adequately monitored in order to decide $\mathrm{hGH}$ treatment at the appropriate time. The possibility that $\mathrm{hGH}$ might stimulate relapse of the original malignancy is a concern in hGH-treated patients. Two separate studies $(76,77)$ have suggested that hGH therapy does not increase the recurrence of disease or the development of other malignancy.

Acknowledgments. The authors acknowledge the collaboration with the following neurosurgery, oncology, and hematology centers of Drs. C. Griscelli and J. F. Hirsch (Hôpital des Enfants Malades), J. M. Zucker and P. Bataini (Institut Curie), J. Lemerle and D. Sarrazin (Institut Gustave Roussy, Villejuif), G. Schaison (Hôpital St-Louis) and D. Machover (Hôpital Tenon). The manuscript was prepared with the skillful secretarial assistance of Mrs. C. Chamot.

\section{REFERENCES}

1. Shalet SM 1983 Disorders of the endocrine system due to radiation and cytotoxic chemotherapy. Clin Endocrinol 18:637-659

2. Shalet SM 1986 Irradiation-induced growth failure. Clin Endocrinol Metab 15:591-606

3. Rappaport R, Fontoura M, Brauner R 1988 Growth hormone secretion and growth in central nervous system irradiated children. In: BB Bercu (eds) Basic and Clinical Aspects of Growth Hormone. Plenum Press, New York, pp 143-155

4. Tan BC, Kunaratnam N 1966 Hypopituitary dwarfism following radiotherapy for nasopharyngeal carcinoma. Clin Radiol 17:302--304

5. Larkins RG, Martin FIR 1973 Hypopituitarism after extracranial irradiation: evidence for hypothalamic origin. Br Med J 1:152-153

6. Perry-Keene DA, Connelly JF, Young RA, Wettenhall HNB, Martin FIR 1976 Hypothalamic hypopituitarism following external radiotherapy for tumours distant from the adenohypophysis. Clin Endocrinol 5:373-380

7. Richards GE, Wara WM, Grumbach MM, Kaplan SL, Sheline GE, Conte FA 1976 Delayed onset of hypopituitarism: sequelae of therapeutic irradiation of central nervous system, eye, and middle ear tumors. J Pediatr 89:553559

8. Shalet SM, Beardwell CG, Morris-Jones PH, Pearson D 1975 Pituitary function after treatment of intracranial tumours in children. Lancet 2:104-107

9. Onayama Y, Abe M, Takahashi M, Yabumoto E, Salamoto T 1975 Radiation therapy of brain tumors in children. Radiology 115:687-693

10. Bamford FN, Morris-Jones PH, Pearson D, Ribeiro CG, Shalet SM, Beardwell CG 1976 Residual disabilities in children trated for intracranial space occupying lesions. Cancer 37:1149-1151

11. Samaan NA, Bakdash MM, Caderao JB, Cangir A, Jesse Jr RH, Ballantyne AJ 1975 Hypopituitarism after external irradiation. Evidence for both hypothalamic and pituitary origin. Ann Intern Med 83:771-777

12. Czernichow P, Cachin O, Rappaport R, Flamant F, Sarrazine D, Schweisguth O 1977 Séquelles endocriniennes des irradiations de la tête et du cou pour tumeurs extracraniennes. Arch Fr Pediatr 34:CLIV-CLXIV
13. Shalet SM, Beardwell CG, Pearson D, Morris-Jones PH 1976 The effect of varying doses of cerebral irradiation on growth hormone production in childhood. Clin Endocrinol 5:287-290

14. Pomarede R, Czernichow P, Zucker JM, Schlienger P, Haye C, Rosenwald JC, Labib A, Rappaport R 1984 Incidence of anterior pituitary deficiency after radiotherapy at an early age: study in retinoblastoma. Acta Paediatr Scand 73:115-119

15. Brauner R, Malandry F, Rappaport R, Zucker JM, Kalifa C, Pierre-Kahn A, Bataini P, Dufier JL, Tar A 1988 Sequential occurrence of endocrine disturbances in children treated for optic gliomas. Pediatr Res 23:111(abstr)

16. Shalet SM, Beardwell CG, Morris-Jones PH, Pearson D 1976 Growth hormone deficiency after treatment of acute leukaemia in children. Arch Dis Child 51:489-493

17. Dickinson WP, Berry DH, Dickinson L, Irvin M, Schedewie H, Fiser RH, Elders MJ 1978 Differential effects of cranial radiation on growth hormone response to arginine and insulin infusion. J Pediatr 92:754-757

18. Romshe CA, Zipf WB, Miser A, Miser J, Sotos JF, Newton WA 1984 Evaluation of growth hormone release and growth hormone treatment in children with cranial irradiation-associated short stature. I Pediatr 104:177181

19. Kirk JA, Raghupathy P, Stevens MM, Cowell CT, Menser MA, Bergin M Tink A, Vines RH, Silink M 1987 Growth failure and growth hormone deficiency after treatment for acute lymphoblastic leukemia. Lancet 1:190193

20. Brauner R, Czernichow P, Rappaport R 1986 Greater susceptibility to hypothalamopituitary irradiation in younger children with acute lymphoblastic leukemia. J Pediatr 108:332

21. Brauner R, Rappaport R, Prevot C, Czernichow P, Zucker JM, Bataini P Lemerle J, Sarrazin D, Guyda HJ 1989 A prospective study of the development of $\mathrm{GH}$ in children given cranial irradiation, and its relation to statura growth. J Clin Endocrinol Metab, 68:346-351

22. Duffner PK, Cohen ME, Voorhess ML, MacGillivray MH, Brecher ML, Panahon A, Gilania BB 1985 Long-term effects of cranial irradiation on endocrine function in children with brain tumors. A prospective study. Cancer 56:2189-2193

23. Lam KSL, Tse VKC, Wang C, Yeung RTT, Ma JTC, Ho JHC 1987 Early effects of cranial irradiation on hypothalamic-pituitary function. $\mathrm{J}$ Clin Endocrinol Metab 64:418-424

24. Sanders JE, Pritchard S, Mahoney P, Amos D, Buckner CD, Withersponn RP, Deeg HJ, Doney KC, Sullivan KM, Appelbaum FR, Storb R, Thomas ED 1986 Growth and development following marrow transplantation for leukemia. Blood 68:1129-1135

25. Leiper AD, Stanhope R, Lau T, Grant DB, Blacklock H, Chessels JM, Plowman PN 1987 The effect of total body irradiation and bone marrow transplantation during childhood and adolescence on endocrine function. $\mathrm{Br} \mathrm{J}$ Hematol 67:419-426

26. Fontoura M, Brauner R, Rappaport R, Fischer A, Quintana E, Zucker JM, Bernaudin F, Vilmer E, Devergie A 1988 Growth and endocrine function after bone marrow transplantation (BMT) with or without total body irradiation (TBI). Pediatr Res 23:111(abstr)

27. Dacou-Voutetakis C, Xypolyta A, Haidas St, Constantinidis M, Papavasiliou C, Zannos-Mariolea L 1977 Irradiation of the head. Immediate effect on growth hormone secretion in children. J Clin Endocrinol Metab 44:791-794

28. Bercu BB, Shulman D, Root AW, Spiliotis BE 1986 Growth hormone (GH) provocative testing frequently does not reflect endogenous GH secretion. J Clin Endocrinol Metab 63:709-716

29. Blatt J, Bercu BB, Gillin JC, Mendelson WB, Poplack DG 1984 Reduced pulsatile growth hormone secretion in children after therapy for acute lymphoblastic leukemia. J Pediatr 104:182-186

30. Chrousos GP, Poplack D, Brown T, O'neill D, Schwade J, Bercu BB 1982 Effects of cranial radiation on hypothalamic-adenohypophyseal function: abnormal growth hormone secretory dynamics. J Clin Endocrinol Metab 54:1135-1139

31. Rose SR, Ross JL, Uriarte M, Barnes KM, Cassorla FG, Cuttler GB 1988 The advantage of measuring stimulated as compared with spontaneous growth hormone levels in the diagnosis of growth hormone deficiency. $N$ Engl J Med 319:201-207

32. Brauner R, Prevot C, Roy MP, Rappaport R 1986 Growth, growth hormone secretion and somatomedin $\mathrm{C}$ after cranial irradiation for acute lymphoblastic leukemia. Acta Endocrinol sup 279:178-182

33. Moëll C, Garwicz S, Westgren U, Wiebe T, Albertsson-Wikland K 1989 Suppressed spontaneous secretion of growth hormone in girls after treatment for acute lymphoblastic leukemia. Arch Dis Child 64:252-258

34. Rappaport R, Fontoura M, Brauner R 1988 Growth hormone secretory dysfunction after hypothalamic and pituitary irradiation. In: EE Müller, D Cocchi, V Locatelli (eds) Advances in Growth Hormone and Growth Factor Research. Pythagora Press, Springer Verlag, Rome, pp 327-337

35. Ahmed SR, Shalet SM, Beardwell CG 1986 The effects of cranial irradiation on growth hormone secretion. Acta Pediatr Scand 75:255-260

36. Costin G 1988 Effects of low-dose cranial radiation on growth hormone secretory dynamics and hypothalamic-pituitary function. Am J Dis Child 142:847-852

37. Lawrence JH, Nelson WO, Wilson H 1937 Roentgen irradiation of the hypophysis. Radiology 29:446-454

38. Arnold A 1954 Effects of x-irradiation on the hypothalamus: a possible explanation for the therapeutic benefits following $x$-irradiation of the hypophysial region for pituitary dysfunction. J Clin Endocrinol Metab 14:859868 
39. Ahmed SR, Shalet SM 1984 Hypothalamic growth hormone releasing factor deficiency following cranial irradiation. Clin Endocrinol 212:483-488

40. Lustig RH, Schriok EA, Kaplan SL, Grumbach MM 1985 Effect of growth hormone-releasing factor on growth hormone release in children with radiation-induced growth hormone deficiency. Pediatrics 76:274-279

41. Shalet SM, Clayton PE, Price DA 1988 Growth impairment following treatment for childhood brain tumours. Acta Paediatr Scand [Suppl] 343;137145

42. Crosnier H, Brauner R, Rappaport R 1988 Growth hormone response to growth hormone releasing hormone (hp GHRH 1-44) as an index of growth hormone secretory dysfunction after prophylactic cranial irradiation for acute lymphoblastic leukemia (24 grays). Acta Paediatr Scand 77:681-687

43. Samaan NA, Vieto R, Schultz PN, Maor M, Meoz RT, Sampiere VA, Cangir A, Ried HL, Jesse Jr RH 1982 Hypothalamic, pituitary and thyroid dysfunction after radiotherapy to the head and neck. Int $J$ Radiat Oncol Biol Phys 8:1857-1867

44. Lam KSL, Wang C, Yeung RTT, Ma JTC, Ho JHC, Tse VKC, Ling N 1986 Hypothalamic hypopituitarism following cranial irradiation for nasopharyngeal carcinoma. Clin Endocrinol 24:643-651

45. Ross RJM, Tsagarakis S, Grossman A 1987 Treatment of growth hormone deficiency with growth-hormone-releasing hormone. Lancet 1:5-8

46. Huang KE 1979 Assessment of hypothalamic-pituitary function in women after external head irradiation. J Clin Endocrinol Metab 49:623-627

47. Rappaport R, Brauner R, Czernichow P, Thibaud E, Renier D, Zucker JM Lemerle J 1982 Effect of hypothalamic and pituitary irradiation on pubertal development in children with cranial tumors. J Clin Endocrinol Metab 54:1164-1168

48. Siris ES, Leventhal BG, Vaitukaitis JL 1976 Effects of childhood leukemia and chemotherapy on puberty and reproductive function in girls. N Engl J Med 294:1143-1146

49. Bajarunas DR, Ghavimi F, Jereb B, Sonenberg M 1980 Endocrine sequelae of antineoplastic therapy in childhood head and neck malignancies. $\mathrm{J}$ Clin Endocrinol Metab 50:329-335

50. Brauner R, Czernichow P, Rappaport R 1984 Precocious puberty after hypothalamic and pituitary irradiation in young children. $N$ Engl $\mathrm{J}$ Med $311: 920$

51. Pasqualini $\Upsilon$, Escobar ME, Domené H, Sackmann-Muriel F, Pavlovsky S, Rivarola MA 1987 Evaluation of gonadal function following long-term treatment for acute lymphoblastic leukemia in girls. Am J Pediatr Hematol Oncol 9:15-22

52. Sanders JE, Buckner D, Leonard JM, Sullivan KM, Withespoon RP, Deeg HJ, Storb R. Thomas ED 1983 Late effects on gonadal function of cyclophosphamide, total body irradiation and marrow transplantation. Transplantation 36:252-255

53. Leiper AD, Stanhope R, Kitching P, Chessels JM 1987 Precocious and premature puberty associated with treatment of acute lymphoblastic leukemia. Arch Dis Child 62:1107-1112

54. Pomarède R, Brauner R, Rappaport R, Czernichow P 1983 Les séquelles thyroïdiennes des radiothérapies pour cancer de la tête et du cou chez l'enfant. In: Actualités carcinologiques. Lemerle J (ed). Masson, Paris, pp 21]-221

55. Clayton PE, Shalet SM, Morris-Jones PH, Price DA 1988 Growth in children treated for acute lymphoblastic leukemia. Lancet 1:460-462

56. Robison LL, Nesbit Jr ME, Sather HN, Meadows AT, Ortega JA, Hammond GD 1985 Height of children successfully treated for acute lymphoblastic leukemia: a report from the late effects study committee of childrens cancer study group. Med Pediatr Oncol 13:14-21

57. Starceski PJ, Lee PA, Blatt J, Finegold D, Brown D 1987 Comparable effects of 1800- and 2400-rads (18- and 24-Gy) cranial irradiation on height and weight in children treated for acute lymphocytic leukemia. Am J Dis Child 141:550-552

58. Wells RJ, Foster MB, D'Ercole AJ, McMillan CW 1983 The impact of cranial irradiation on the growth of children with acute lymphocytic leukemia. Am J Dis Child 137:37-39

59. Sainsbury CPQ, Newcombe RG, Hugues IA 1985 Weight gain and height velocity during prolonged first remission from acute lymphoblastic leukemia. Arch Dis Child 60:832-836

60. Berry DH, Elders MJ, Crist WM, Land V, Lui V, Sexauer AC, Dickinson L 1983 Growth in children with acute lymphocytic leukemia: a pediatric oncology group study. Med Pediatr Oncol 11:39-45

61. Berglund G, Karlberg J, Marky I, Mellander L 1985 A longitudinal study of growth in children with acute lymphoblastic leukemia. Acta Paediatr Scand 74:530-533

62. Shalet SM, Price DA, Beardwell CG, Morris-Jones PH, Pearson D 1979 Normal growth despite abnormalities of growth hormone secretion in children treated for acute leukemia. J Pediatr 94:719-722

63. Brauner R, Rappaport R, Fontoura M, Leverger G, Zucker JM, Griscelli C 1988 Sustained growth in spite of radiation induced GHD occurs only after low hypothalamo-pituitary dose. Pediatr Res 24:526(abstr)

64. Moëll C 1988 Disturbed pubertal growth in girls after acute leukemia: a relative growth hormone insufficiency with late presentation. Acta Paediatr Scand (Suppl) 343:162-166

65. Brauner R, Czernichow P, Rappaport R 1985 Croissance staturale après irradiation du systéme nerveux central pour médulloblastome de la fosse postérieure. Analyse rétrospective de 45 observations. Arch Fr Pediatr 42:219-223

66. Shalet SM, Gibson B, Swindell R, Pearson D 1987 Effect of spinal irradiation on growth. Arch Dis Child 62:461-464

67. Brown IH, Lee TJ, Eden OB, Bullimore JA, Savage DCL 1983 Growth and endocrine function after treatment for medulloblastoma. Arch Dis Child 58:722-727

68. Probert JC, Parker BR, Kaplan HS 1973 Growth retardation in children after megavoltage irradiation of the spine. Cancer 32:634-639

69. Sunderman CR, Pearson HA 1969 Growth effects of long-term antileukemic therapy. J Pediatr 75:1058-1062

70. Shalet SM, Whitehead E, Chapman AJ, Beardwell CG 1981 The effects of growth hormone therapy in children with radiation-induced growth hormone Acta Pediatr Scand 70:81-6

71. Lannering B, Marky I, Mellander L, Albertsson-Wikland K 1988 Growth hormone secretion and response to growth hormone therapy after treatment for brain tumor. Acta Peadiatr Scand [Suppl] 343:146-151

72. Cowell CT, Quigley CA, Moore B, Kirk JA, Bergin M, Jimenez N, Stevens MM, Howard NJ, Menser MA, Silink M 1988 Growth and growth hormone therapy of children treated for leukemia. Acta Pediatr Scand [Suppl] 343:152-161

73. Mugnier E, Ployard F, Roy MP, Fermanian J, Rappaport R 1985 Résultats du traitement par l'hormone de croissance humaine chez les enfants insuffisants hypophysaires âgés de moins de 7 ans. Arch Fr Pediatr 42:671-676

74. Clayton PE, Shalet SM, Price DA 1988 Growth response to growth hormone therapy following cranial irradiation. Eur J Pediatr 147:593-596

75. Clayton PE, Shalet SM, Price DA 1988 Growth response to hormone therapy following craniospinal irradiation. Eur J Pediatr 147:597-601

76. Arslanian SA, Becker DJ, Lee PA, Drash AL, Foley TP Jr 1985 Growth hormone therapy and tumour recurrence. Am J Dis Child 139:347-350

77. Clayton PE, Shalet SM, Gattamaneni HR, Price DA 1987 Does growth hormone cause relapse of brain tumors. Lancet 1:711-713 